\title{
The DM-scope registry: a rare disease innovative framework bridging the gap between research and medical care
}

\author{
Marie De Antonio ${ }^{1,2}$, Céline Dogan ${ }^{1}$, Ferroudja Daidj ${ }^{1}$, Bruno Eymard ${ }^{1}$, Jack Puymirat ${ }^{3}$, Jean Mathieu ${ }^{4}$, \\ Cynthia Gagnon ${ }^{4,5}$, Sandrine Katsahian ${ }^{2,6}$, the Filnemus Myotonic Dystrophy Study Group, Dalil Hamroun ${ }^{7}$ and \\ Guillaume Bassez ${ }^{1,8^{*}}$
}

\begin{abstract}
Background: The relevance of registries as a key component for developing clinical research for rare diseases (RD) and improving patient care has been acknowledged by most stakeholders. As recent studies pointed to several limitations of RD registries our challenge was (1) to improve standardization and data comparability; (2) to facilitate interoperability between existing RD registries; (3) to limit the amount of incomplete data; (4) to improve data quality. This report describes the innovative concept of the DM-Scope Registry that was developed to achieve these objectives for Myotonic Dystrophy (DM), a prototypical example of highly heterogeneous RD. By the setting up of an integrated platform attractive for practitioners use, we aimed to promote DM epidemiology, clinical research and patients care management simultaneously.

Results: The DM-Scope Registry is a result of the collaboration within the French excellence network established by the National plan for RDs. Inclusion criteria is all genetically confirmed DM individuals, independently of disease age of onset. The dataset includes social-demographic data, clinical features, genotype, and biomaterial data, and is adjustable for clinical trial data collection. To date, the registry has a nationwide coverage, composed of 55 neuromuscular centres, encompassing the whole disease clinical and genetic spectrum. This widely used platform gathers almost 3000 DM patients (DM1 $n=2828$, DM2 $n=142)$, both children $(n=322)$ and adults $(n=2648)$, which accounts for $>20 \%$ of overall registered DM patients internationally. The registry supported 10 research studies of various type i.e. observational, basic science studies and patient recruitment for clinical trials.

Conclusion: The DM-Scope registry represents the largest collection of standardized data for the DM population. Our concept improved collaboration among health care professionals by providing annual follow-up of quality longitudinal data collection. The combination of clinical features and biomolecular materials provides a comprehensive view of the disease in a given population. DM-Scope registry proves to be a powerful device for promoting both research and medical care that is suitable to other countries. In the context of emerging therapies, such integrated platform contributes to the standardisation of international DM research and for the design of multicentre clinical trials. Finally, this valuable model is applicable to other RDs.
\end{abstract}

Keywords: Myotonic dystrophy, Rare disease registry, Platform, Medical care, Research

\footnotetext{
* Correspondence: guillaume.bassez@aphp.fr

${ }^{1}$ Neuromuscular Reference Center, AP-HP, Pitié-Salpêtrière Hospital, Paris, France

${ }^{8}$ INSERM, Research Center in Myology, Sorbonne University, Paris, France

Full list of author information is available at the end of the article
}

(c) The Author(s). 2019 Open Access This article is distributed under the terms of the Creative Commons Attribution 4.0 International License (http://creativecommons.org/licenses/by/4.0/), which permits unrestricted use, distribution, and reproduction in any medium, provided you give appropriate credit to the original author(s) and the source, provide a link to the Creative Commons license, and indicate if changes were made. The Creative Commons Public Domain Dedication waiver (http://creativecommons.org/publicdomain/zero/1.0/) applies to the data made available in this article, unless otherwise stated. 


\section{Background}

Over the last few years, several international initiatives have aimed to organize clinical research, patient care and health planning in the field of rare diseases (RD) [1-5]. The lack of relevant knowledge and experience concerning many RDs requires better cooperation and infrastructure. A critical step focuses, as a priority, on Rare Disease Registries (RDRs). Indeed, most stakeholders consider registries to be a strategic tool to develop research and improve knowledge in the field of RDs. The European Platform for RDRs project (EPIRARE) has addressed issues associated with the registration of RDs. This project overviewed the current situation and experience of national RDRs in Europe [6, 7]. The study was used to classify RDRs [8], assess and characterize their quality [9], resulting in a set of core recommendations for RD patient registration and data collection [10-12].

The DM-Scope registry was created in 2008, at the beginning of the European initiatives [1] in response to the complex clinical and genetic characteristics of Myotonic Dystrophy (DM), a prototypical example of highly heterogeneous $\mathrm{RD}$. At this time, the knowledge of underlying molecular mechanisms was growing. However, the high variability of clinical features in DM created particular challenges in the design of clinical studies and for health management.

DM encompasses two rare genetic diseases belonging to the family of neuromuscular disorders: Myotonic Dystrophy type 1 (DM1) and Myotonic Dystrophy type 2 (DM2). DM1 is the most common adult muscular dystrophy with a prevalence of about 6.5/100000 [13]. DM2 is more or less prevalent than DM1 according to certain countries $[14,15]$. Both types are recognisable by their multisystemic involvement $[14,16]$ and their high clinical inter- and intra-individual variability due to the nature of the underlying atypical mutation i.e. an unstable nucleotide repeat expansion [16-22]. The clinical spectrum is particularly large in DM1 with an anticipation phenomenon between generations and is expressed in five different clinical forms, ranging from neonatal to late adult-onset forms [23]. The correlation between phenotype and molecular mechanisms is better understood [24-26] but the part of genetic or epigenetic factors causing the variability of DM1 multisystemic involvement in a given individual remains to be better defined [27-36].

In the last few decades, the increasing understanding of DM pathogenesis has led to the development of several therapeutic approaches [37-40]. It is therefore necessary to gather relevant clinical, genetic and epidemiological data in a large DM population. The evaluation of the efficiency of new therapies requires identification of endpoint measures and informative biomarkers to assess their effect on disease progression. Of note, despite previous studies, the natural history of DM has not yet been fully described [41-43].

During the last decade, we developed, in accordance with European recommendations, a shareable and interoperable framework (DM-Scope system) to promote a quality multicentre collection of data from a large cohort of French DM patients. As DM patients cognitive impairment limits their own contribution to data collection, we developed an integrative platform to promote the contribution of practitioners from the French RD Reference centres [44]. Based on a reciprocal collaboration, DM-Scope system standardizes optimal data collection and facilitates the use of collected data for both medical care and clinical research.

The primary purposes of this paper are to present: (1) the concept of the DM-Scope registry to overcome at most the challenges of RDRs; (2) the innovative tools of the integrative platform; (3) the clinical network activity; (4) the main characteristics of the DM cohorts i.e. demographic-social conditions, professional categories, clinical forms, and mortality.

\section{Material and methods \\ DM-scope registry concept}

The DM-Scope registry was developed in France in 2008. The main objective was to increase the epidemiological knowledge in DM, to harmonize patients medical follow-up, and to facilitate selection and enrolment of DM patients in clinical trials, particularly in a multicentre setting. The multi-sites implementation benefited from the national plan for RDs initiated in 2005 in France with the designation of 131 centres of reference at a national level, and 502 centres of competence at a regional level. DM belongs to FILNEMUS, the neuromuscular RDs axis of the national plan.

The DM-scope concept was to create an integrative Information Technology (IT) platform providing tools to allow the collection of data during routine clinical management while promoting clinical research. A common core data set (CDS) appropriate for the DM population was created by collaboration between French and Canadian scientists. We also ensured that the CDS could enhance translational research in DM such as natural history studies, validation of outcomes measures and genotype-phenotype correlations. The DM-Scope system proposes specific tools to summarize clinical visit data and to help health-care practitioners in routine medical care.

This framework has been built to be shareable, interoperable and open to researchers and clinicians to favour a synergistic network in the DM community.

\section{Governance}

DM-Scope was funded by Association Française contre les Myopathies (AFM)-Telethon patients association. 
Registry leadership consists of a co-ownership between AFM-Telethon and "Assistance Publique-Hôpitaux de Paris" (AP-HP), as well as an internal steering committee and an external scientific advisory committee. The internal steering committee includes principal and co-investigators, physicians and a DM representative from the patient group. The external scientific advisory committee consists of two expert scientists.

\section{Ethical and legal issues}

DM-Scope registry has been approved by the French data protection authority (National Commission on Informatics and Liberty [CNIL]) (approval reference number: \#1282122, date of approval: 2008). Patients are anonymously registered in a reversible way for practitioners only. The consent procedure was approved by the national ethic committee CCTIRS (Advisory Committee on Information Processing in Material Research in the Field of Health). The adult patients received an information letter and granted their verbal informed consent. The legal guardians and children received an information letter and legal guardians signed a written informed consent. The paediatric section was approved by Tours university hospital ethics committee (approval reference number: \#2014-025, date of approval: 2014).

\section{Patient and data collection}

DM-Scope registry collects relevant clinical and epidemiological data on a standardized form during routine medical evaluation performed in French neuromuscular reference centres. Only patients with confirmed genetic diagnosis were included and data was collected by health-care practitioners during their annual clinical visit. CDS is close to the common data element recommended by the EPIRARE project [11]. The DM-Scope form is shared with the Quebec registry to promote international research. The information is broadly divided into the following sections: demographic features (date of birth, gender, parental details, place of birth, place of residence, willingness to be contacted to participate in a future clinical study and date and reason of death), diagnosis, natural history (including description of the pregnancy, the newborn period, neurodevelopmental conditions for children), past medical history, education, social and professional impact of the disease, neuromuscular symptoms, orthopaedic deformations and facial dysmorphism for children, cardiac troubles, respiratory defects, digestive problems, endocrine dysfunction, current medications and interest for clinical research (current and past participation in clinical trials). Prioritisation of data collection is defined by a set of mandatory, prioritised and optional items.

Health-care practitioners or clinical research assistants (CRA) input data either online into the DM-Scope system or onto a paper form received and entered by the curating centre (Fig. 1).

Patients can be informed about research studies, advances in knowledge of the disease and easily connected with expert neuromuscular centres. Information is available on the DM-Scope website (www.dmscope.fr). In a next step, patients should also request to be included in the registry using a self-recorded form to report data such as quality of life. This complementary enrolment allows the extension of the registration of DM individuals to patients who are not followed in RD reference centres.

\section{Security of data}

Recorded data stored on secured file servers maintained by a clinical research unit at Montpellier hospital (France). This team is responsible for development, maintenance and the security of numerous registries and cohorts. The DM-Scope system consists of a robust security infrastructure to support authentication, confidentiality and data integrity. To access the system, every user is assigned a personal user name and password. The online input and access to the data are restricted to the practitioners or CRA who have a personal login. The access codes are generated by administrators, once the user has signed a written agreement. Health-care practitioners have an online and secure access to the data of the DM patients they follow. Patients are identified by the first three letters of their first and second name, gender and date of birth. However, only fully anonymous data are available to researchers and for analysis - all enrolled participants have a DM-Scope ID which is automatically generated.

In the near future, the registry plan to be connected with the national RD public health general registry (BAMARA) [45, 46].

\section{Data use and research applications}

Investigators from expert centres are required to submit a research protocol to the internal steering committee. Data analysis and recruitment of patients starts once the project has been unanimously approved by the internal steering committee. All feasibility studies and identification of eligible patients for recruitment in clinical studies are performed by the coordinating centre staff. Publication policy and authorship composition are defined a priori. All-contributors are included in the authorship.

\section{Quality insurance procedures}

Homogeneous data collection for new participants is ensured by an initial training program. CRA pays special attention to assess the quality of collected data and respect the standardized protocol. Each clinician is 


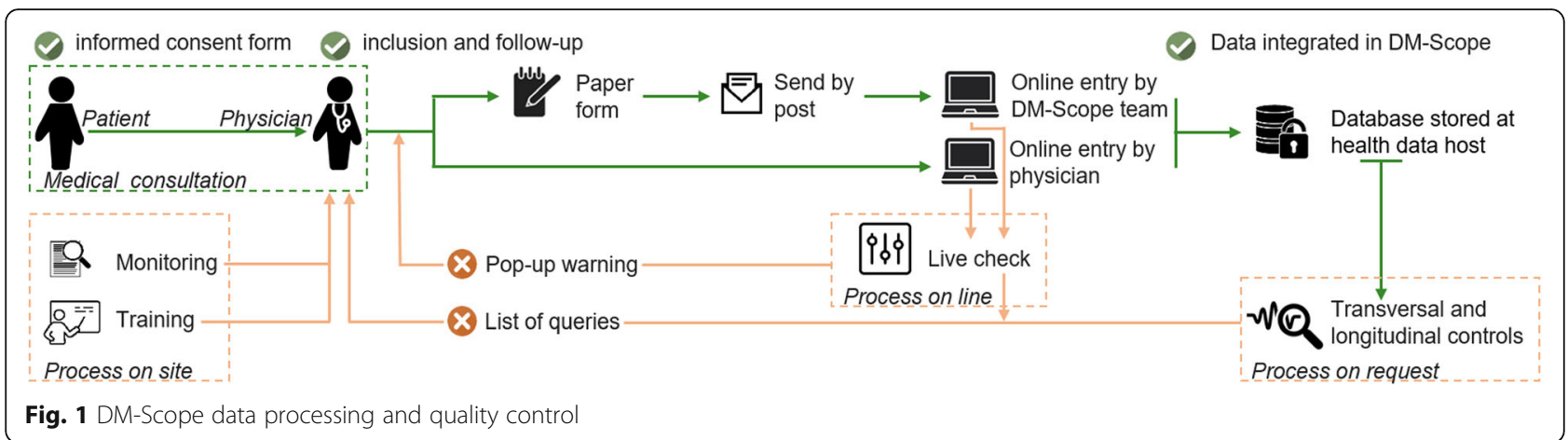

responsible for the content and quality of collected information.

Data input is controlled at three levels (Fig. 1). First, quality control occurs at the online input. Several data constraints have been integrated into the DM-Scope system which filter and generate automatic alerts when inconsistent data have been entered. For example, duplicate records are not allowed, consultation dates have to be superior to birth date, etc. In the case where data is entered by the coordinating centre staff, the automatically generated queries are sent to participating centres for resolution. Second quality control is performed on request, an $\mathrm{R}$ algorithm included in the DM-Scope platform allows a list of transversal and longitudinal inconsistencies and the generated queries sent to participant centres for resolution to be visualised. Last quality control is site monitoring. Regular visits to neuromuscular centres allow completion of undelivered data and clarify queries. Monitoring of collected data is facilitated by a specific tool created in the DM-Scope system. Furthermore, this platform provides a synopsis with complete and incomplete data per visit and per patient.

\section{Database architecture}

DM-Scope registry is available on a secured website (www.dmscope.fr). Included tools are secure source applications with restricted data access to previously recorded professionals. Database is designed as web-server architecture and is accessible from anywhere at anytime. The statistical software R (version 3.5.0) is connected with the database.

The web-server was developed by 4D (version v17). 4D updates every 18 months. Daily backups are done by a program in the database settings. Each backup includes the structure and the data files for recovering the database automatically. The system is compliant with European Union's General Data Protection Regulation (EU GDPR) and data are stored in an authorised system hosting personal health data.

\section{Functionalities and database interface}

The interface layout has been designed to facilitate navigation and allows the use of various tools integrated into the system. Available functions vary according to the user type: general user, professional user and curators.

\section{General user interface}

The DM-Scope home page describes DM diseases, the DM-scope platform (including aims, guidelines, networks, research projects, underlying source documents, information links...), and news in the DM-field.

\section{Professional interface}

The DM-Scope system provides tools to optimize clinical evaluations (Fig. 2, left part). Home page for health-care practitioners includes a list of patients. Physicians or CRA can complete or create a new patient follow-up. Patient health is summarized in a dashboard that helps physicians to display a detailed overview of the collected longitudinal data, to edit synopsizes or medical reports, to visualize graphs following the severity of symptoms and refer to automatic index facilities. There is reciprocity between users and the coordinating centre to improve the data management system and enhance their intrinsic motivation.

\section{Curator interface}

In addition to displaying data in an organized manner, the curators have several tools to follow the network activity, to screen eligible patients for clinical studies and to identify patients with available biomaterials at AFM-Genethon Biobank. Supplementary functions allow summaries and graphic displays. Statistics and graphics are renewed at each DM-Scope update to report activity in each centre and to characterize the current French DM population.

\section{Statistical analyses}

Cross-sectional analysis was performed using $\mathrm{R}$ 3.5.0 software (the R Foundation for Statistical Computing, Vienna, Austria). Descriptions are given in number and 


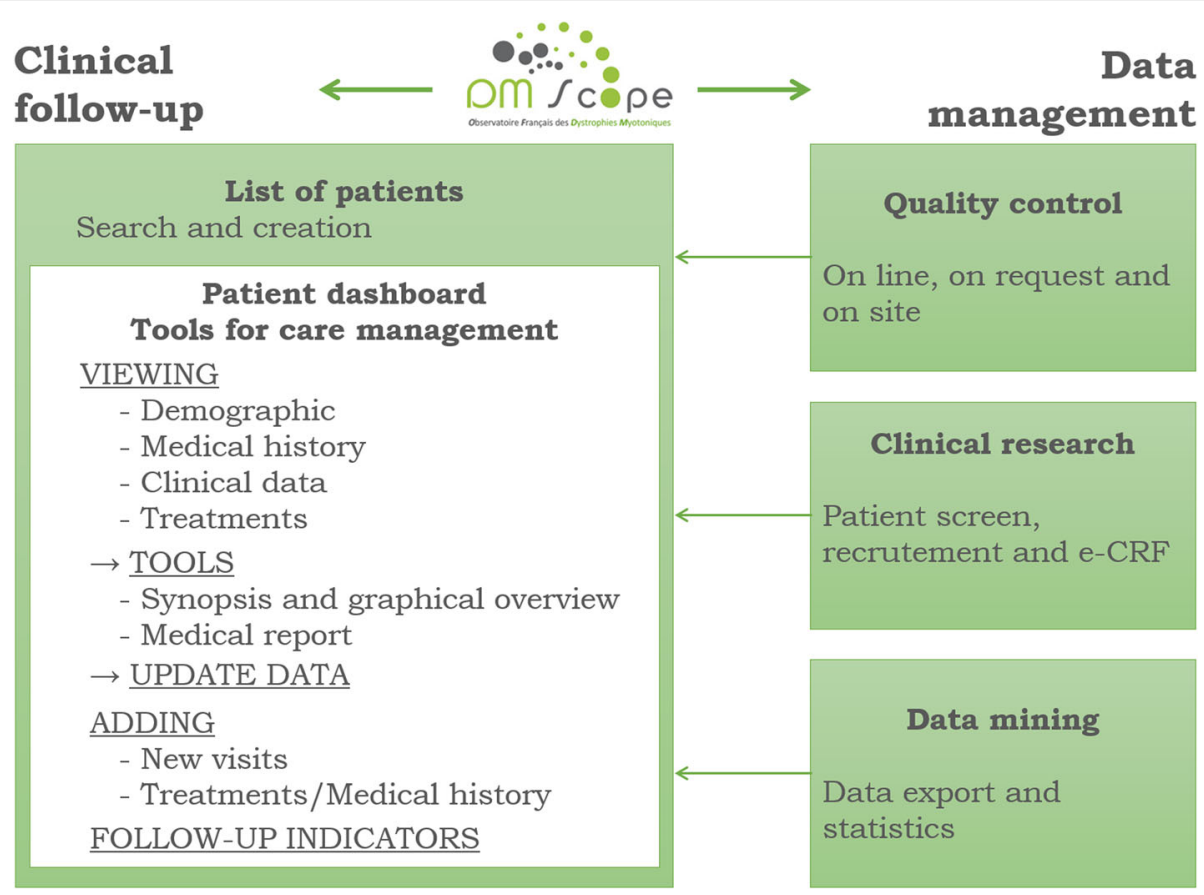

Fig. 2 Functionalities and database interface

percentage $\mathrm{N}$ (\%) for qualitative variables, in mean and standard deviation (SD) for quantitative variables or in median and interquartile range [Q1; Q3] in the case of a non-gaussian distribution. Missing data from subjects who had incomplete follow-up data were imputed using the Last-Observation-Carried-Forward method. Geographical distribution was presented using the cartography package (version 2.1.2) [47, 48]. Information on the French territorial departments and regions was acquired from the French National Geographic Institute $\left(\right.$ GEOFLA $^{\circ}$ 2.1). Sociodemographic data of the French population was based on French National Institute of Statistics and Economic Studies [49]. Survival analysis was performed using Kaplan-Meier curves. Date of inclusion in the study is defined as the date of the first symptom. The end date is the date of death or last follow-up. Cox proportional hazards models stratified by centres with a gamma frailty term is used to assess random effects across the contributing centres $[50,51]$.

\section{Results}

\section{DM-scope registry activity}

\section{A nationwide coverage}

DM-Scope registry has a nationwide coverage (Fig. 3a). The distribution of DM patients is non-homogenous with a lower proportional representation of patients in the East of France since corresponding expert centres joined the registry more recently. The relative ratio of DM patients to the general population in each region of France was uneven. Five regions showed the highest density of DM patients (Fig. 3b): such as Limousin, Pays de la Loire, Champagne-Ardennes, Bretagne and Aquitaine.

Standardized data from DM enrolled patients were collected by 55 French RD expert centres ( 26 childhood and 29 adult centres). Fourteen of the 26 paediatric centres enrolled respectively more than $10 \mathrm{DM} 1$ childhood patients (Fig. 3c). Half of the DM1 paediatric cohort was included by the 7 biggest centres: Dijon, Lille, Lyon (Bron), Paris (Necker), Vannes, Montpellier and Clermont-Ferrand. Thirteen of the 29 adult centres have more than 80 patients (Fig. 3d). Half of the adult cohort is managed by the 7 biggest adult centres: Paris (Pitié-Salpêtrière), Nantes, Toulouse, Montpellier, Angers, Bordeaux and Lille.

\section{Regular enrolment of DM patients and annual data update} The DM-scope registry has enrolled almost 3000 DM patients since 2008 (Fig. 4). Inclusion of the 2970 patients has been regular up to now (green line). The collected data have been annually updated since 2010 . Between 2008 and 2018, more than half of the enrolled DM patients (53.3\%) have been followed-up at least once, $30.9 \%$ at least twice, and $17.9 \%$ at least three times.

\section{The DM-scope registry, a useful platform to promote DM research}

DM-scope registry has facilitated the design, the recruitment of patients and the access to available biomaterials 


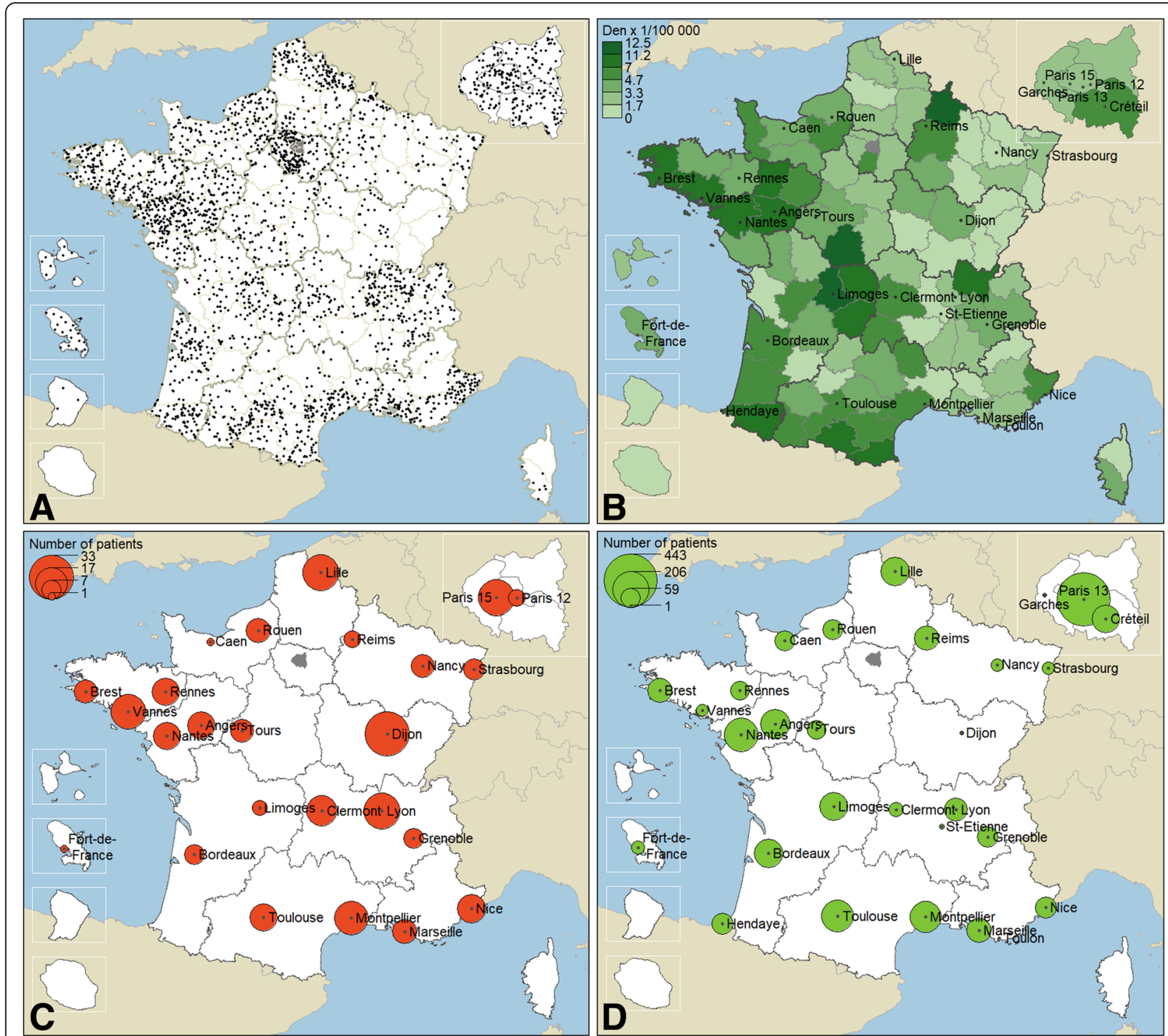

Fig. 3 Cartography of place of residence of enrolled DM participants. a The individual representation $(N=2875)$. Each dot refers to one patient place of residence and dots position is allocated to a random position in the corresponding department (top left). $\mathbf{b}$ The regional distribution according to the density of population ( $\mathrm{N}=2875)$. Darker the green is, more the DM is prevalent in the department (top right). c Distribution of DM-Scope Registry enrolled patients among paediatric French neuromuscular expert centres (26 centres, $N=255$ ). The number of enrolled patients is spot-size dependent (bottom left). $\mathbf{d}$ Distribution of DM-Scope Registry enrolled patients among adult French neuromuscular expert centres (29 centres, $N=2620$ ). The number of enrolled patients is spot-size dependent (bottom right)

in various type of research studies $(n=10)$. Observational studies have led to refine the DM1 clinical classification [23], to identify gender as a modifying factor of the DM phenotype [52], altogether contributing to registry harmonization $[53,54]$ and to the definition of guidelines for medical care [55]. Other collaborative observational studies contributed to improve knowledge on myotonic stiffness in adults with DM1 [56], ophthalmologic defects [57], pyscho-cognitive aspects [58] and DM1 paediatric forms [59]. DM-scope registry also contributed to basic research by the identification of a unique interrupted genetic variant in two atypical DM1 pedigrees [60]. Finally, the DM-Scope registry was instrumental for the screening and recruitment of participants in interventional studies. One on-going study focuses on the impact of the early introduction of non-invasive ventilation [Clinical trial \#NCT01225614]. A phase 2 pharmacological trial reported the benefit of metformin for locomotion [61]. In the European Optimistic clinical trial, the efficiency of the registry was evidenced by fast recruitment of 71 DM1 patients within a short timeframe (6 months) and a low screening failure rate $[62,63]$. 


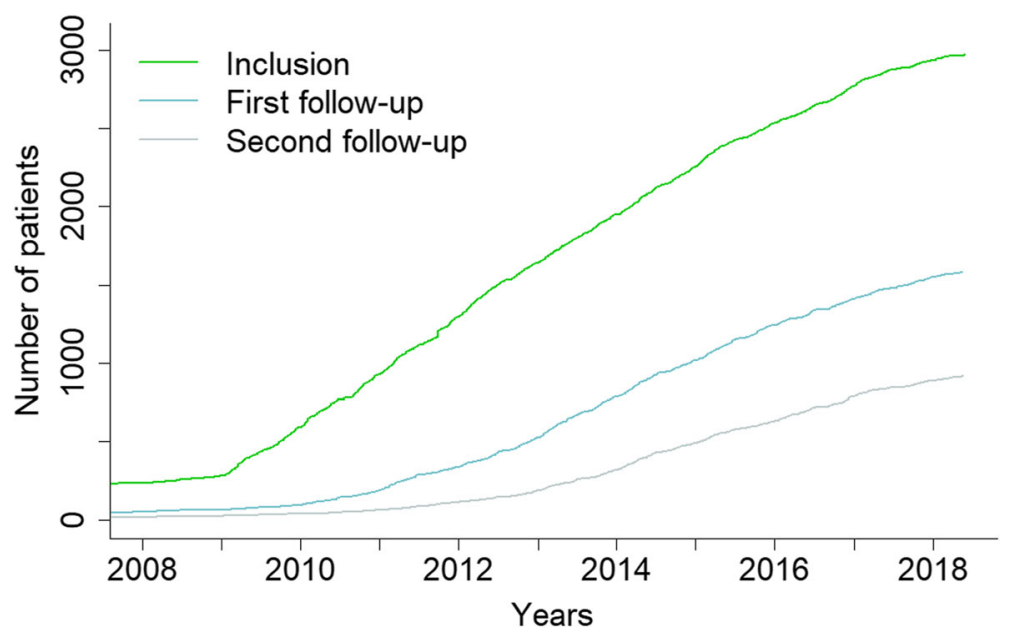

Fig. 4 Cumulative number of participants in the DM-Scope Registry. The green line represents the number of included DM patients and the blue/grey line the number of first/second followed-up DM patients over time

\section{DM-scope registry covers a well-characterized representative population \\ Demography (Table 1)}

The DM-Scope registry includes 2828 DM1 patients (2506 adults and 322 children) and 142 DM2 adult patients. At the last visit, 62 DM1 children became adults and 95 patients died (86 DM1 adults, 5 DM1 children and 4 DM2 patients).

In 2018, the registry counts 2876 living patients (2737 DM1 and 138 DM2). Demographic results revealed that women accounted for a slightly greater percentage of enrolled patients in both DM subtypes. The mean age of

Table 1 Demographic characteristics, diagnosis and genetic of DM enrolled patients in DM-Scope registry

\begin{tabular}{|c|c|c|c|c|}
\hline Variable & Level & DM1 $(N=2737)$ & $\mathrm{DM} 2(N=138)$ & Total $(N=2875)$ \\
\hline \multicolumn{5}{|l|}{ Demography } \\
\hline Sex & Female & $1453(53.1 \%)$ & 79 (57.2\%) & $1532(53.3 \%)$ \\
\hline Age at the last visit & mean (sd) & $41.1(16.0)$ & $54.5(14.2)$ & $41.7(16.1)$ \\
\hline Adults & Age $>18$ years & $2482(90.7 \%)$ & $138(100.0 \%)$ & $2620(91.1 \%)$ \\
\hline \multirow[t]{2}{*}{ Marital status } & Single & $1080(47.3 \%)$ & $34(28.8 \%)$ & $1114(46.4 \%)$ \\
\hline & missing & $200(8.1 \%)$ & $20(14.5 \%)$ & $220(8.4 \%)$ \\
\hline \multicolumn{5}{|l|}{ Diagnosis and genetic } \\
\hline \multirow[t]{2}{*}{ Age of first symptoms } & mean (sd) & $23.5(15.9)$ & $38.1(16.0)$ & $24.2(16.2)$ \\
\hline & missing & $490(17.9 \%)$ & $24(17.4 \%)$ & $514(17.9 \%)$ \\
\hline \multirow[t]{2}{*}{ Age at clinical diagnosis, yrs } & mean (sd) & $32.5(14.8)$ & $48.3(13.5)$ & $33.4(15.2)$ \\
\hline & missing & $519(19.0 \%)$ & $9(6.5 \%)$ & $528(18.4 \%)$ \\
\hline \multirow[t]{2}{*}{ Age at molecular diagnosis, yrs } & mean (sd) & $33.4(16.0)$ & $50.6(14.0)$ & $34.3(16.4)$ \\
\hline & missing & $532(19.4 \%)$ & $13(9.4 \%)$ & $545(19.0 \%)$ \\
\hline \multirow[t]{2}{*}{ Delay between diagnosis, years } & median [iqr] & $8.6[3.2,17.2]$ & $10.8[4.4,19.9]$ & $8.9[3.3,17.4]$ \\
\hline & missing & $1230(44.9 \%)$ & 40 (29\%) & $1270(44.2 \%)$ \\
\hline \multirow[t]{2}{*}{ Mutation size ${ }^{a}$} & median [iqr] & $550[300,900]$ & $4000[2750,5000]$ & - \\
\hline & missing & $584(21.3 \%)$ & 71 (56.5\%) & - \\
\hline \multirow[t]{2}{*}{ Transmission } & Paternal & 1100 (56.9\%) & 27 (39.7\%) & 1127 (56.4\%) \\
\hline & missing & 805 (29.4\%) & $70(50.7 \%)$ & 875 (30.4\%) \\
\hline
\end{tabular}

${ }^{\mathrm{a}} \mathrm{CTG}$ mutation for DM1 and CCTG mutation for DM2

Descriptions are given in number and percentage N (\%) for qualitative variables; in mean and standard deviation (SD) or in median and interquartile range [Q1;

Q3] for quantitative variables. Number of missing data is written in italic 
patients at the last visit is 41.1 yrs. (16.0) in DM1 and 54.5 yrs. (14.2) in DM2. 47.3\% of DM1 patients compared to $28.8 \%$ of DM2 patients live alone.

\section{Diagnosis and genetic characteristics}

The clinical manifestations were the first causes of diagnosis in DM patients (47.5\% for DM1 and 65.7\% DM2). However, a substantial number of DM1 patients are diagnosed by familial genetic counselling (43.9\% DM1 and $32.4 \%$ DM2). Only few patients, exclusively DM1, were identified after the occurrence of a child with a congenital form (7.2\% DM1). Diagnoses were made on average at 32.5 yrs. (14.8) in DM1 and 48.3 yrs. (13.5) in DM2 for clinical diagnosis and on average at 33.4 yrs. (16.0) in DM1 and 50.6 yrs. (14.0) in DM2 for molecular diagnosis (Table 1). The delay between the first symptom and the molecular diagnosis is on average at 8.5 yrs. [3.0, 17.0] in DM1 and 10.8 yrs. [4.4, 19.9] in DM2.

Genetic tests were available in $77.4 \%$ of diagnosed patients. The median mutation size was 550 [300, 900] (min-max: 41-5000) CTG repeats in DM1 and 4000 [2750, 5000] (min-max: 185-23,100) CCTG repeats in DM2. In contrast with DM2, where the transmission is mainly maternal (60.3\% of transmissions), DM1 is more often transmitted by the father (56.9\% of transmissions).

\section{Clinical spectrum}

The DM-Scope registry covers a large clinical spectrum as previously described [13]. On average, the first symptom generally appeared at the age of 23.5 (15.9) in DM1 and at the end of the third decade in DM2 (38.1 yrs. (16.0)). Disease onset occurred over a very large age range (min-max: 0-73 yrs. in both types). The French DM1 population included the five clinical forms classified on the basis of age at onset: congenital (onset $<1$ month; $230(9.0 \%)$ ), infantile (onset between 1 month and 10 yrs.; (424 (16.5\%)), juvenile (onset between 11 yrs. and 20 yrs.; (724 (28.2\%)), adult (onset between 21 yrs. and 40 yrs.; $810(31.6 \%)$ ) and late form (onset after 40 yrs.; $376(14.7 \%))$.

\section{Education and employment (Table 2)}

Only DM1 adult patients were still students $(4.5 \%$ adult DM1, $0 \%$ adult DM2). The mean age at the end of education was similar in the two DM subtypes ( 18.8 yrs. (3.9) in DM1 and 18.9 yrs. (3.9) in DM2). DM1 patients were more frequently schooled in specialized educational conditions (14.6\% adult DM1, 2.3\% adult DM2). The proportion of DM2 patients having an educational level ISCED $>3$ was higher than in DM1 (51.8\% in DM2, $39.2 \%$ in adult DM1).

Table 2 Educational and employment of DM enrolled patients in the DM-Scope registry

\begin{tabular}{|c|c|c|c|c|c|}
\hline & \multirow[t]{3}{*}{ Level } & \multicolumn{2}{|l|}{$\mathrm{DM} 1$} & \multirow[t]{2}{*}{ DM2 } & \multirow[t]{2}{*}{ All } \\
\hline & & Children & Adults & & \\
\hline & & $(N=255)$ & $(N=2482)$ & $(N=138)$ & $(N=2875)$ \\
\hline \multicolumn{6}{|l|}{ Education } \\
\hline \multirow[t]{2}{*}{ In education at the last visit } & Yes & $24(96.0 \%)$ & $97(4.5 \%)$ & $0(0.0 \%)$ & $121(5.3 \%)$ \\
\hline & missing & $230(90.2 \%)$ & $336(13.5 \%)$ & $42(30.4 \%)$ & $608(21.1 \%)$ \\
\hline \multirow[t]{2}{*}{ Age at education end, years } & mean $(s d)$ & - & $18.8(3.9)$ & $18.9(3.9)$ & $18.8(3.9)$ \\
\hline & missing & 255 (100\%) & $1819(73.3 \%)$ & $99(71.7 \%)$ & $2173(75.6 \%)$ \\
\hline \multirow[t]{2}{*}{ Educational environment } & Specialized & $80(40.4 \%)$ & $284(14.6 \%)$ & $2(2.3 \%)$ & $366(16.5 \%)$ \\
\hline & missing & $57(22.4 \%)$ & $543(21.9 \%)$ & $52(37.7 \%)$ & $652(22.7 \%)$ \\
\hline \multirow[t]{2}{*}{ Final education on ISCED scale } & level > 3 & $5(3.4 \%)$ & $729(39.2 \%)$ & $43(51.8 \%)$ & 777 (37.2\%) \\
\hline & missing & $107(42 \%)$ & $622(25.1 \%)$ & $55(39.9 \%)$ & $784(27.3 \%)$ \\
\hline \multicolumn{6}{|l|}{ Employment } \\
\hline \multirow[t]{2}{*}{ In activity at the last visit } & Yes & - & $654(27.6 \%)$ & $27(25.0 \%)$ & $681(27.5 \%)$ \\
\hline & missing & - & $111(4.5 \%)$ & $30(21.7 \%)$ & $141(4.9 \%)$ \\
\hline \multirow[t]{2}{*}{ Time of activity } & Part-time & - & $201(34.2 \%)$ & $7(28.0 \%)$ & $208(33.9 \%)$ \\
\hline & missing & - & $66(2.7 \%)$ & $2(1.4 \%)$ & $68(2.4 \%)$ \\
\hline \multirow[t]{2}{*}{ Professional environment } & Specialized & - & $137(27.6 \%)$ & $1(4.5 \%)$ & $138(26.6 \%)$ \\
\hline & missing & - & $158(6.4 \%)$ & $5(3.6 \%)$ & $163(5.7 \%)$ \\
\hline \multirow[t]{2}{*}{ Reason for unemployment } & Due to the disease & - & $933(70.8 \%)$ & $24(35.8 \%)$ & $957(69.1 \%)$ \\
\hline & missing & - & 399 (16.1\%) & $14(10.1 \%)$ & $413(14.4 \%)$ \\
\hline
\end{tabular}


Only one third of DM adults were employed at time of last visit (27.6\% in adult DM1, 25.0\% in DM2). DM1 individuals had a part-time employment more frequently than those with DM2 (34.2\% of DM1 adults, $28.0 \%$ of patients in DM2). Among DM1 active adults, 27.6\% worked in a specialized professional environment, and only one among DM2 patient. Unemployment is mainly due to the disease (70.8\% in DM1; 35.8\% of DM2). All social-professional categories were represented in the two DM forms. More than one half of the DM active adults were employees or workmen (68.9\% in DM1, $57.6 \%$ in DM2), $16.7 \%$ of DM patients worked in intermediate professions (16.7\% in DM1, $18.2 \%$ in DM2) and few DM patients had positions with responsibilities, such as shopkeepers or company heads (4.4\% in DM1, 6.1\% in DM2). DM2 patients were more represented in executive and intellectual professions (9.9\% in DM1, 18.2\% in DM2).

\section{Survival analysis with heterogeneity between centres}

Survival analyses were performed on 1476 patients and 92 events. The Kaplan-Meier survival curve for the total cohort is illustrated in Fig. 5. Median follow-up is $17.4[9.6 ; 28.0]$ years, the probability of survival at 30 years is 0.94 .

Among the 55 centres, 33 centres did not report any death cases and 7 centres recorded more than 5 dead patients. Survival analysis is performed on 33 centres ( $\geq 10$ patients). Figure 5 shows the heterogeneity between the 20 centres which recorded death status and the variance of random effects is 0.22 .

\section{Discussion}

This report describes the DM-Scope registry, an innovative concept that overcomes most of RD registries limitations. Indeed, health authorities pointed to main limitations of RD registries including underreporting of outcomes, missing data, and/or inadequate follow-up. Robustness of gathered data depends on the quality of data entry, the number of enrolled patients, the diversity of their demographic and disease characteristics, including age-annotated manifestations, and the retention of recruited patients [1-4].

DM-Scope registry overall model is based on (1) an innovative IT platform that provides tools for clinicians to facilitate the management of DM patients, and on (2) the network of neuromuscular expert centres established by the national RDs plan in France. The registry federates RD expert physicians, from 55 French neuromuscular expert centres, and promotes a longitudinal standardised data collection. To our knowledge, such platform is a unique example that helps to optimize medical care as well as facilitate research in RD. By enabling the input of multidisciplinary expert physicians and limiting the contribution of cognitively impaired DM patients, this registry ensures highest quality of data. While other DM registries have been established [64] the DM-Scope registry is the largest one with almost 3000 DM enrolled patients accounting for more than $20 \%$ of overall registered DM patients internationally [53]. Furthermore, the registry collects the whole range of demographic and phenotypic characteristics of this $\mathrm{RD}$ condition. Indeed, standardized data span from congenital patients at birth to late onset adult patients. In

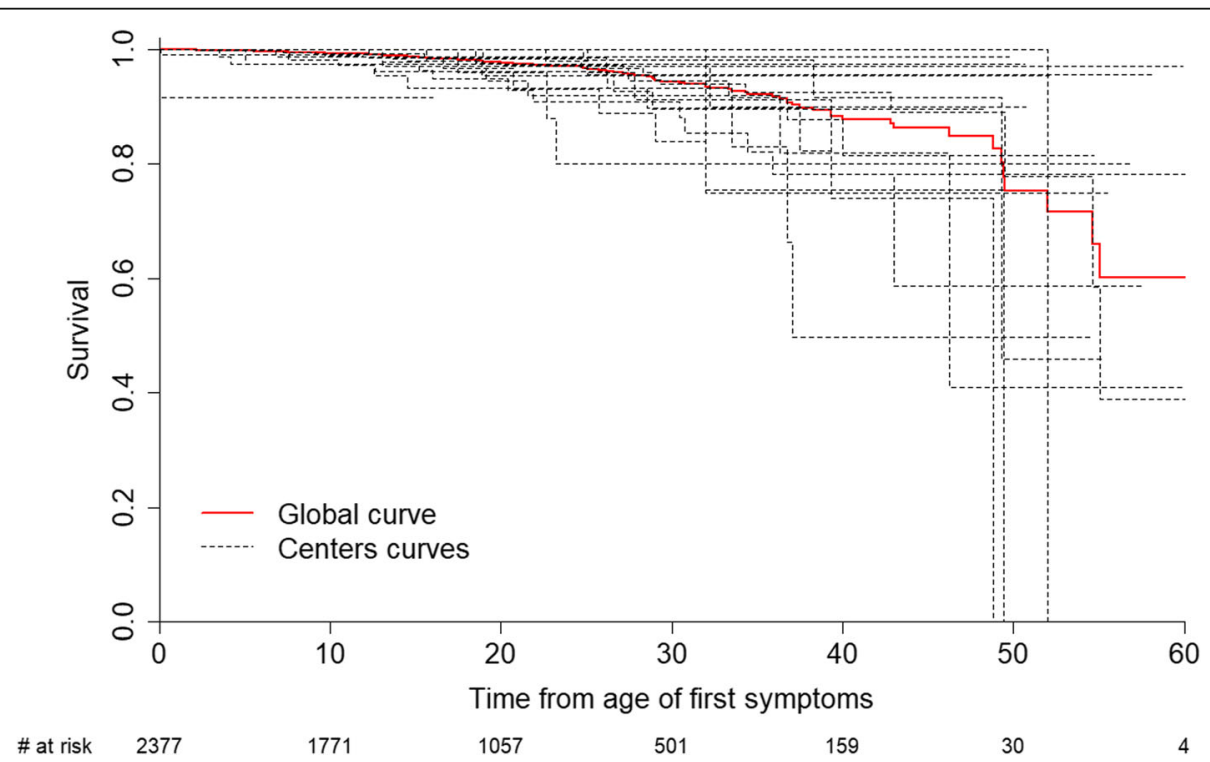

Fig. 5 Kaplan-Meier curves for all-cause mortality. The red line indicates the survival of the overall registry DM population; the dark dotted lines represent survival of subgroups in the 33 individual neuromuscular centres (only centres including more than 10 patients are selected) 
addition, the platform includes three levels-quality insurance procedure.

The registry coverage is nationwide though some regions are under-represented. This is likely related to the activity of the neuromuscular expert centres and more recent partnered centres should homogenise the national distribution in the future. Studies to assess the DM prevalence are limited [13] and the exact prevalence in France is unknown. In addition, the DM disease is not listed for genetic screening in most countries. Therefore national coverage of our registry contributes to estimate the distribution of DM individuals and regional differences. Some differences were observed in the relative distribution of DM patients according to the general population density in some geographic areas suggesting that the prevalence of DM is uneven across France. For example, in the Basque region a high DM1 frequency was observed which is consistent with the report by López de Munain et al. [45]. To confirm such regional disparities in France, we plan to analyse complementary data from the national BAMARA registry [46]. It should be noted that DM-Scope and BAMARA registries are not designed for prevalence studies since they are not intended to collect the complete disease population.

Recently, we decided to record death status which allows (1) to estimate the severity of the disease; (2) to minimise bias in cross-sectional studies due to loss of follow-up due to death; (3) for patient screening and enrolment in clinical trials; (4) to assess various prognostic factors of death. Survival analyses in DM are scarce with no recent population cohort data existing. Our results showed an annual frequency of death consistent with previous reports [65]. In our case, the number of deceased patients is likely under-estimated since the vital status recording was more recently introduced leading to no record of death being reported by many centres. An accurate identification of death is limited since it is not part of annual clinical follow-up management. We expect to further improve the registry by identifying patients not seen $(>3$ years) by clinician determination of the patient status: lost to follow-up vs death. In addition, complementary analyses from administrative national databases [66] will significantly improve survival estimations.

As part of the national RD plan, the DM-Scope registry will allow longitudinal comparison of medical practice between $\mathrm{RD}$ expert centres with the purpose of promoting a harmonization of DM medical care nationally as well as contributing to healthcare guidelines for DM.

The DM-Scope Registry covers the large clinical and genetic spectrum of DM patients $[14,16]$ with the representation of all social and professional conditions. The registry provides opportunities to characterize large DM cohorts of adults or children, to clarify genotype-phenotype correlations, to study the social and professional consequences of DM as well as to compare the DM1 and DM2 genetic entities. While encompassing all disease organ and system involvement, the registry currently lacks items describing the cognitive impairment. Over the past few years, international workshops $[67,68]$ have focused on how to assess central nervous system involvement. Some time-consuming neuropsychological tests are currently discussed and require validation for future integration into registry dataset. Missing data are mainly related to optional items and seem randomly distributed.

The DM-Scope registry has drawbacks including (1) the lack of items related to the cognitive impairment, (2) the underreporting of deceased cases, and (3) missing data.

Our platform has already proven to be a key instrument for promoting clinical studies and generating data for medical care guidance in DM1. In fact, the registry substantially facilitated DM translational research by (1) refining the DM1 clinical classification; (2) accessing to available biomaterials for molecular basic research studies; (3) the design and the recruitment of patients in both observational and interventional studies; and (4) producing evidence-based material for care guidelines in adult and childhood DM populations. Future longitudinal analyses from the DM-Scope registry will be conducted to refine the clinical characteristics of the DM population.

The transferable strengths of the registry rely in the fact that it is a shareable and interoperable framework which promotes multicentre high quality data collection in a large population. In this way, the DM-Scope registry has recently evolved into an international consortium (named iDM-Scope) to harmonise the French and Quebec cohorts. Such data standardization allows the comparison of DM characteristics in two different populations. Data harmonization helps to improve translational research including natural history studies, biomarker identification and outcome measures and facilitates the recruitment of patients in upcoming transnational multicentre trials. It represents a first step to contribute to cross-border healthcare in DM. In addition, DM-scope concept can serve as a model to other RDs.

\section{Conclusion}

The DM-scope registry overcomes some of the main challenges of RD registries. By facilitating the contribution of clinicians and creating a standardized data collection, our system provides robust data nationwide. The link between clinical features, genotype, available biomaterial and trial datasets, creates this platform a powerful 
device for the harmonization of international DM network activities and for the design of multicentre studies. The DM-Scope registry has been proven effective for various translational research studies and also in clinical trials. Finally, the DM-scope concept can serve as a generalizable model to other countries and to other rare diseases.

\section{Abbreviations}

AFM: "Association Française contre les myopathies"; AP-HP: "Assistance Publique des Hôpitaux de Paris"; BAMARA: National Rare disease Public Health general Registry; CCTG: Cytosine, Cytosine, Thymine, Guanosine; CCTIRS: "Comité consultatif sur le traitement de l'information en matière de recherche"; CDS: Core Data Set; CNIL : "Commission nationale de l'informatique et des libertés"; CRA: ClinicalResearch Assistant; CTG: Cytosine, Thymine, Guanosine; DM: Myotonic Dystrophy; DM1: Myotonic Dystrophy type I; DM2: Myotonic Dystrophy type II; EPIRARE: European Plateform for Rare Disease Registries Project; EU GDPR: European Union's General Data Protection Regulation; ISCED: International Standard Classification of Education; IT: Information Technology; RD: Rare diseases; RDR: Rare disease Registries; SD: Standard deviation

\section{Acknowledgments}

We would like to thank all of the patients and staff members that participated in collecting data at clinical sites, particularly: Sylvie Brimont, Margaret Bruey, Sylvie Estrade, Katia Gillo, Maryse, Maclet-bourrienne, Bénédicte Pontier, Magalie Pointud, Pascale Poitou, Candice Rudelle and Aurore Siffert. We would like also to thank Hélène Moussu, Catherine Eng, Caroline Stalens, Melinda Gyenge and Simone Birnbaum who reviewed the manuscript. We are grateful to the AFM-Téléthon for its financial support. The French myotonic dystrophy clinical research network of Filnemus is composed of (The group has to be searchable through their individual PubMed records): ARNE BES Marie Christine (Neurologie, Pôle neurosciences, Hôpital Pierre-Paul Riquet, Toulouse, France), ATTARIAN Shahram (Service de Neurologie Hôpital de La Timone 1, Marseille, France) AUBE-NATHIER AnneCatherine (Consultation multidisciplinaire maladies neuromusculaires pour adultes Département de neurologie, CHU d'Angers, France), AUDIC Frédérique, (Service de neurologie pédiatrique, pneumologie pédiatrique et médecine infantile, Hôpital de La Timone, Marseille, France), BACH Nathalie (Service de pédiatrie médicale, pôle Femme Enfant, CHU, Caen, France), BARNERIAS Christine (Consultation myologie, Cliniques des maladies du développement, Hôpital Necker-Enfants Malades, Paris, France), BEDAT-MILLET AnneLaure (Service de neurologie, CHU Nicolle, ROUEN Cedex, France), BEHIN Anthony (Institut de myologie, hôpital Pitié-Salpêtrière, Paris, France), BELLANCE Remi (Centre hospitalier universitaire Fort de France), BENYAOU Rabah (Institut de myologie, hôpital Pitié-Salpêtrière, Paris, France), BOMBARD Véronique (Service de médecine physique et de réadaptation, Hôpital Sébastopol, Reims, France), BOUHOUR Françoise (Centre SLA-service d'électroneuromyographie et pathologies neuromusculaires, hôpital Pierre Wertheimer, $\mathrm{CHU}$ de Lyon, BRON, France), BOUTTE Celia (Pôle de psychiatrie et neurologie, CHU de Grenoble site Nord-Hôpital Albert Michallon, Grenoble, France), BOYER François (Service de médecine physique et de réadaptation, Hôpital Sébastropol, Reims), CANCES Claude (Service de pédiatrie - Neurologie et infectiologie, Pôle enfants, Hôpital des enfants, CHU Purpan, Toulouse, France), CHABROL Brigitte (Service de neurologie pédiatrique, pneumologie pédiatrique et médecine infantile, Hôpital de La Timone, Marseille, France), CHANSON Jean-Baptiste (Hôpital de jour - Neurologie -Pôle tête-cou / CETD, Hôpital de Hautepierre, Strasbourg, France), CHAPON Françoise (Laboratoire d'Anatomie Pathologie - Neuropathologie CHU Hôpital Côte de Nacre, Caen, France), CHASSERIAU Raphaële (Laboratoire d'explorations fonctionnelles CHU de Nantes, France), CINTAS Pascal (Neurologie, Pôle neurosciences, Hôpital Pierre-Paul Riquet, Toulouse, France), COBO Ana-Maria (Hôpital Marin, Hendaye. France), COLOMBERT Vanessa (Centre hospitalier Bretagne Atlantique, Vannes, France), CRUZ Marie-Carmen (Neurologie, Pôle neurosciences, Hôpital Pierre-Paul Riquet, Toulouse, France), CUISSET Jean-Marie (Service de neuropédiatrie, Hôpital Roger-Salengro, Lille, France), DESCHAMPS Romain (Centre hospitalier universitaire, unité de neuromyologie, Fort de France cedex), DESGUERRE Isabelle (Consultation myologie, Cliniques des maladies du développement, Hôpital Necker-Enfants Malades, Paris, France),
DURIGNEUX Julien (Pôle mère-enfant, neuropédiatrie et neurochirgurgie de l'enfant, CHU d'Angers, France), DUVAL Fanny (Service de neurologie- Hôpital Pellegrin, Bordeaux, France), ESPIL Caroline (Service de pédiatrie médicale, Hôpital Pellegrin, Bordeaux, France), FAFIN Catherine (Hôpitaux pédiatriques de Nice CHU-Lenval, Nice, France), FEASSON Léonard (Consultation Médecine physique et réadaptation enfant, Hôpital Bellevue, Saint-Etienne, France), FRADIN Mélanie (Pôle de pédiatrie médico-chirurgicale et génétique clinique CHU de Rennes - Hôpital Sud, Rennes, France), FURBY Alain (Consultation Médecine physique et réadaptation enfant, Hôpital Bellevue Saint-Etienne, France), GOLDENBERG Alice (Unité de Génétique Clinique, CHU Nicolle, Rouen, France), GROTTO Sarah (Unité de Génétique Clinique, CHU Nicolle, Rouen, France), GHORAB Karima (Service de neurologie C H U Dupuytren 2, Limoges, France), GUYANT-MARECHAL Lucie (Unité de Génétique Clinique, CHU Nicolle, Rouen, France), HERON Delphine (Institut de myologie, hôpital Pitié-Salpêtrière, Paris, France), ISAPOF Arnaud (Service de neuropédiatrie et pathologie du développement, Hôpital Trousseau, Paris, France), JACQUINPIQUES Agnes (Service de neurophysiologie enfants et adultes, Hôpital F. Mitterrand, Dijon, France), JOURNEL Hubert (CHBA Centre hospitalier Bretagne Atlantique, Vannes, France), LAFORET Pascal (Institut de myologie, hôpital Pitié-Salpêtrière, Paris, France), LAGRUE Emmanuelle (Service de neuropédiatrie et handicaps, CHRU Clocheville, Tours, Fra,ce), LAROCHE-RAYNAUD Cécile (Hôpital de la mère et de l'enfant, Dominique Larrey, Limoges, France), LAUGEL Vincent (Service de pédiatrie médico-chirurgicale, Hôpital de Hautepierre, Strasbourg, France), LEBEAU Françoise (Service de neurologie CHU Dupuytren 2, Limoges, France), MAGOT Armelle (Laboratoire d'explorations fonctionnelles, Hôtel Dieu 1, Nantes, France), MANEL Véronique (Exploration fonctionnelle neuropédiatrique, Hôpital Femme Mère enfant, Bron, France), MAYER Michèle (Service de neuropédiatrie et pathologie du développement, Hôpital Trousseau, Paris, France), MERCIER Sandra (Laboratoire d'explorations fonctionnelles, Hôtel Dieu1, Nantes, France), MENARD Dominique (Consultation neuromusculaire, CHU Hôpital Pontchaillou 2, Rennes, France), MICHAUD Maud (Service de neurologie, hôpital central, Nancy. Paris), MINOT Marie-Christine (Consultation neuromusculaire, CHU Hôpital Pontchaillou 2 . Rennes, France), MORALES Raul-Juntas (Pôle neuroscience tête et cou - Hôpital Gui de Chauliac Montpellier, France), NADAJ-PAKLEZA Aleksandra (Consultation multidisciplinaire maladies neuromusculaires pour adultes Département de neurologie, Hôpital Larrey, Angers, France), NOURY Jean-Baptiste (Service de neurologie. Hôpital d'instruction des armées Clermont-Tonnerre, Brest. France), PASQUIER Laurent (Génétique médicale CHU Hôpital Sud, Rennes, France), PELLIEUX Sybille (Service de médecine physique et réadaptation, Hôpital Trousseau Tours, France), PEREON Yann (Laboratoire d'explorations fonctionnelles, Hôtel Dieu Nantes, France), PERRIER Julie (Laboratoire d'explorations fonctionnelles, Hôtel Dieu Nantes, France), PEUDENIER Sylviane (Département de pédiatrie et département de génétique médicale, Hôpital Morvan, Brest, France), PREUDHOMME Marguerite (Service de médecine et de réadaptation, Centre Hospitalier Régional Universitaire de Lille2, Lille, France), POUGET Jean (Service de Neurologie Hôpital de La Timone 1, Marseille, France), QUIJANO-ROY Susana (Service de Neurologie et réanimation pédiatriques CHU Paris IdF Ouest - Hôpital Raymond Poincaré, Garches, France), RAGOT-MANDRY Sylvie (Service d'explorations fonctionnelles pédiatriques, Hôpital de Brabois, Vandœuvre-Lès-Nancy, France), RICHELME Christian (Service de de pédiatrie et de neuropédiatrie, Hôpital I'Archet 2, Pôle Femme Mère Enfant, Nice, France), RIVIER François (Département de neuropédiatrie, Hôpital Gui de Chauliac, Montpellier, France), SABOURAUD Pascal (Service de pédiatrie A - Unité de neurologie pédiatrique. American Memorial Hospital, Reims, France), SACCONI Sabrina (Système Nerveux Périphérique, Muscle et SLA. Pôle Neurosciences. Hôpital Pasteur 2, Nice, France), SALORT-CAMPANA Emmanuelle (Centre de Référence Maladies Neuromusculaires et SLA Hôpital de la Timone, Marseille Cedex 20, France), SARRET Catherine (Pôle de pédiatrie, Hôpital d'Estaing, Clermont-Ferrand, France), SCHAEFFER Stéphane (Laboratoire d'Anatomie Pathologie - Neuropathologie CHU Hôpital Côte de Nacre, Caen, France), SOLE Guilhem (Service de neurologie- Hôpital Pellegrin, Bordeaux, France), STOJKOVIC Tanya (Institut de myologie, hôpital Pitié-Salpêtrière, Paris, France), TAITHE Frédéric (Service de neurologie, CHU,ClermontFerrand, France), TESTARD Hervé (Pôle de Psychiatrie, Neurologie et Rééducation Neurologique, CHU Grenoble Alpes, Grenoble, France), TIFFEREAU Vincent (Service de médecine et de réadaptation, Centre Hospitalier Régional Universitaire de Lille2,Lille.France), URTIZBEREA Andoni (Hôpital Marin, Hendaye, France), VANHULLE Catherine (Service de neurologie pédiatrique. PavilIon Femme, mère et enfant. Hôpital Charles Nicolle, Rouen. France), VIAL Christophe (Centre SLA-service d'électroneuromyographie et pathologies neuromusculaires, hôpital Pierre Wertheimer, CHU de Lyon, BRON, France), 
WALTHER-LOUVIER Ulrike (Département de neuropédiatrie, Hôpital Gui de Chauliac, Montpellier, France), ZAGNOLI Fabien (Service de neurologie. Hôpital d'instruction des armées Clermont-Tonnerre, Brest. France).

\section{Funding}

All phases of this study were supported by AFM-Téléthon fondation.

\section{Availability of data and materials}

The datasets generated and analysed during the current study are not publicly available due the co-ownership between AFM-Téléthon and "Assistance Publique Hôpitaux de Paris" (AP-HP) and the legal statement. Researchers willing to access generated anonymised data are requested to contact the corresponding author and to sign a data access agreement. Request for access will be reviewed by the DM-scope registry scientific committee.

\section{Authors' contributions}

Wrote the first draft of the manuscript: MDA, CD. Contributed to the writing of the manuscript: SK, GB. Performed statistical analyses: MDA. Conceived and designed DM-Scope database: GB, CD, MDA, DH, JP, CG, JM, BE. Collected and monitored DM-Scope data: CD, the Filnemus Myotonic Dystrophy Study Group. All authors read and approved the final manuscript.

\section{Ethics approval and consent to participate}

The DM-Scope registry received the approval of the Advisory Committee on Information Processing in Material Research in the Field of Health (CCTIRS) and the National Commission for Computing and Liberties (CNIL).

\section{Consent for publication}

The adult patient received an information letter and granted their verbal informed consent. The legal guardians and the child received an information letter and the legal guardians signed a written informed consent.

\section{Competing interests}

The authors declare that they have no competing interests.

\section{Publisher's Note}

Springer Nature remains neutral with regard to jurisdictional claims in published maps and institutional affiliations.

\begin{abstract}
Author details
${ }^{1}$ Neuromuscular Reference Center, AP-HP, Pitié-Salpêtrière Hospital, Paris, France. ${ }^{2}$ INSERM U1138, Centre de Recherche des Cordeliers, Sorbonne University, Paris Descartes University, Paris, France. ${ }^{3}$ Human Genetics, CHUQ/ CHUL, Québec, Canada. ${ }^{4}$ Groupe de recherche interdisciplinaire sur les maladies neuromusculaires (GRIMN), CIUSSS du Saguenay-Lac-St-Jean, Québec, Canada. ${ }^{5}$ Centre de recherche

Charles-Le-Moyne-Saguenay-Lac-St-Jean sur les innovations en santé (CR-CSIS), Faculté de médecine et des sciences de la santé, Université de Sherbrooke, Québec, Canada. ${ }^{6}$ Unit of Epidemiology and Clinical Research, AP-HP, Georges-Pompidou Hospital, Paris, France. University Institute of Clinical Research, CHU, Montpellier, France. ${ }^{8}$ INSERM, Research Center in Myology, Sorbonne University, Paris, France.
\end{abstract}

\section{Received: 25 January 2019 Accepted: 6 May 2019}

\section{Published online: 03 June 2019}

\section{References}

1. Aymé S, Rodwell C. The European Union Committee of Experts on Rare Diseases:three productive years at the service of the rare disease community. Orphanet J Rare Dis. 2014;9(1):30. https://doi.org/10.1186/17501172-9-30

2. Council recommendation on an action in the field of rare diseases. 2009. https://eur-lex.europa.eu/LexUriServ/LexUriServ.do?uri=OJ:C:2009:151:0007: 0010:EN:PDF

3. European Union Committee of experts on Rare Diseases Recommendations on quality criteria for centers of expertise for rare diseases in Member states. 2011 http://eucerd.eu/?post_type=document\&p=1224

4. European Union Committee of Experts on Rare diseases: European Union Committee of Experts on rare diseases: recommendations on European reference Networks for rare diseases. 2013 http://www.eucerd.eu/?post_ type $=$ document $\& p=2207$
5. Dawkins HJS, Draghia-Akli R, Lasko P, Lau LPL, Jonker AH, Cutillo CM, Rath A, Boycott KM, Baynam G, Lochmüller H, Kaufmann P, Le Cam Y, Hivert V. Austin $\mathrm{CP}$; international rare diseases research consortium (IRDiRC). Progress in rare diseases research 2010-2016: an IRDiRC perspective. Clin Transl Sci. 2018;11(1): 11-20. https:/doi.org/10.1111/cts.12501 Epub 2017 Oct 23. Review.

6. Taruscio D, Gainotti S, Mollo E, Vittozzi L, Bianchi F, et al. The current situation and needs of rare disease registries in Europe. Public Health Genomics. 2013;16(6):288-98.

7. Taruscio D, Vittozzi L, Choquet R, Heimdal K, Iskrov G, et al. Nationalregistries of rare diseases in Europe: an overview of the currentsituation and experiences. Public Health Genomics. 2015;18(1):20-5.

8. Santoro M, Coi A, Lipucci Di Paola M, Bianucci AM, Gainotti S, et al. Rare diseaseregistriesclassification and characterization: a data mining approach. Public health. Genomics. 2015;18(2):113-22.

9. Coi A, Santoro M, Villaverde-Hueso A, Lipucci Di Paola M, Gainotti S, et al. The quality of rare disease registries: evaluation and characterization. Public Health Genomics. 2016:19(2):108-15.

10. Kodra Y, Weinbach J, Posada-de-la-Paz M, Coi A, Lemonnier SL, van Enckevort D, Roos M, Jacobsen A, Cornet R, Ahmed SF, Bros-Facer V, Popa V, Van Meel M, Renault D, von Gizycki R, Santoro M, Landais P, Torreri P, Carta C, Mascalzoni D, Gainotti S, Lopez E, Ambrosini A, Müller H, Reis R, Bianchi F, Rubinstein YR, Lochmüller H, Taruscio D. Recommendations for improving the quality of rare disease registries. Int J Environ Res Public Health. 2018;15(8).

11. Taruscio D, Mollo E, Gainotti S, de la Paz Posada M, Bianchi F, et al. The EPIRARE proposal of a set of indicators and common data elements for the European platform for rare disease registration. Arch Public Health. 2014; 72(1):35.

12. EUCERD Core recommendations on rare disease patient registration and data collection. 2015.http://www.eucerd.eu/?page_id=13

13. Prevalence and incidence of rare diseases. Bibliographic data. 2016. http:// www.orpha.net/orphacom/cahiers/docs/GB/Prevalence_of_rare_diseases_ by_alphabetical_list.pdf

14. Harper P. Myotonic dystrophy, 3rd edition-major problems in neurology. In: Medicine; 2001.

15. Suominen $T$, Bachinski LL, Auvinen $S$, Hackman P, Baggerly KA Angelini C, Peltonen L, Krahe R, Udd B. Population frequency of myotonic dystrophy: higher than expected frequency of myotonic dystrophy type 2 (DM2) mutation in Finland. Eur J Hum Genet. 2011; 19(7):776-82.

16. Day JW, Ricker K, Jacobsen JF, Rasmussen LJ, Dick KA, Kress W, Schneider C, Koch MC, Beilman GJ, Harrison AR, Dalton JC, Ranum LP. Myotonic dystrophy type 2: molecular, diagnostic and clinical spectrum. Neurology. 2003;60(4):657-64

17. Aslanidis C, Jansen G, Amemiya C, Shutler G, Mahadevan M, et al. Cloning of the essential myotonic dystrophy region and mapping of the putative defect. Nature. 1992;355(6360):548-51.

18. Brook JD, McCurrach ME, Harley HG, Buckler AJ, Church D, et al. Molecular basis of myotonic dystrophy: Expansion of a trinucleotide (CTG) repeat at the $3^{\prime}$ end of a transcript encoding a protein kinase family member. Cell. 1992:68(4):799-808

19. Fu YH, Pizzuti A, Fenwick RG Jr, King J, Rajnarayan S, et al. An unstable triplet repeat in a gene related to myotonic muscular dystrophy. Science. 1992;255(5049):1256-8

20. Mahadevan M, Tsilfidis C, Sabourin L, Shutler G, Amemiya C, et al. Myotonic dystrophy mutation: an unstable CTG repeat in the $3^{\prime}$ untranslated region of the gene. Science. 1992;255(5049):1253-5.

21. Ranum LP, Rasmussen PF, Benzow KA, Koob MD, Day JW. Genetic mapping of a second myotonic dystrophy locus. Nat Genet. 1998;19(2):196-8.

22. Liquori CL, Ricker K, Moseley ML, Jacobsen JF, Kress W, Naylor SL, Day JW, Ranum LP. Myotonic dystrophy type 2 caused by a CCTG expansion in intron 1 of ZNF9. Science. 2001;293(5531):864-7.

23. De Antonio M, Dogan C, Hamroun D, Mati M, Zerrouki S, Eymard B, Katsahian S, Bassez G. French Myotonic Dystrophy Clinical Network. Unravelling the myotonic dystrophy type 1 clinical spectrum: A systematic registry-based study with implications for disease classification. Rev Neurol (Paris). 2016;172(10):572-80 Review.

24. Miller JW, Urbinati CR, Teng-Umnuay P, Stenberg MG, Byrne BJ, Thornton CA, Swanson MS. Recruitment of human muscleblind proteins to (CUG)(n) expansions associated with myotonicdystrophy. EMBO J. 2000;19(17):4439-48. 
25. Wheeler TM, Thornton CA. Myotonic dystrophy: RNA-mediated muscle disease. CurrOpin Neurol. 2007;20(5):572-6 Review.

26. Cho DH, Tapscott SJ. Myotonic dystrophy: emerging mechanisms for DM1 and DM2. Biochim Biophys Acta. 2007;1772(2):195-204 Review.

27. Novelli G, Gennarelli M, Menegazzo E, Mostacciuolo ML, Pizzuti A, et al. (CTG) $n$ triplet mutation and phenotype manifestations in myotonic dystrophy patients. Biochem Med Metab Biol. 1993;50(1):85-92.

28. Eguchi I, Koike R, Onodera O, Tanaka K, Kondo H, et al. Correlation between degrees of the CTG repeat expansion and clinical features of myotonic dystrophy. Rinsho Shinkeigaku. 1994;34(2):118-23.

29. Jaspert A, Fahsold R, Grehl H, Claus D. Myotonic dystrophy: correlation of clinical symptoms with the size of the CTG trinucleotide repeat. J Neurol. 1995;242(2):99-104.

30. Gennarelli M, Novelli G, Andreasi Bassi F, Martorell L, Cornet M, et al. Prediction of myotonic dystrophy clinical severity based on the number of intragenic [CTG] n trinucleotide repeats. Am J Med Genet. 1996;65(4):342-7.

31. Martorell $L$, Johnson $K$, Boucher CA, Baiget $M$, et al. Somatic instability of the myotonic dystrophy (CTG) $n$ repeat during human fetal development. Hum Mol Genet. 1997;6(6):877-80.

32. Utsugisawa K, Yamagata M, Nagane $Y$, Tohgi H, et al. Effects of CTG repeat expansion on quantitative muscle histopathology in myotonic dystrophy. Nihon Rinsho. 1997;55(12):3214-8.

33. Gharehbaghi-Schnell EB, Finsterer J, Korschineck I, Mamoli B, Binder BR. Genotype-phenotype correlation in myotonic dystrophy. Clin Genet. 1998; 53(1):20-6.

34. Marchini C, Lonigro R, Verriello L, Pellizzari L, Bergonzi P, et al. Correlations between individual clinical manifestations and CTG repeat amplification in myotonic dystrophy. Clin Genet. 2000;57(1):74-82.

35. Garcia-Gomez T, Maestre J, Garrido ML, Vilches R, Fernandez MD, et al. Genotype-phenotype correlation in myotonic dystrophy and prediction of clinical seriousness. Rev Neurol. 1999;29(6):499-502.

36. Morales F, Couto JM, Higham CF, Hogg G, Cuenca P, et al. Somatic instability of the expanded CTG triplet repeat in myotonic dystrophy type 1 is a heritable quantitative trait and modifier of disease severity. Hum Mol Genet. 2012;21 (16):3558-67.

37. Paulson H. Repeat expansion diseases. Handb Clin Neurol. 2018;147:105-23. https://doi.org/10.1016/B978-0-444-63233-3.00009-9 Review.

38. Echenne B, Bassez G. Congenital and infantile myotonic dystrophy. Handb Clin Neurol. 2013;113:1387-93.

39. Yum K, Wang ET, Kalsotra A. Myotonic dystrophy: disease repeat range, penetrance, age of onset, and relationship between repeat size and phenotypes. Curr Opin Genet Dev. 2017;44:30-7. https://doi.org/10.1016/j. gde.2017.01.007 Epub 2017 Feb 14. Review.

40. Myotonic dystrophies. An update on clinical aspects, genetic, pathology, and molecular pathomechanisms. Meola G, Cardani R Biochim Biophys Acta. 2015;1852(4):594-606. https://doi.org/10.1016/j.bbadis.2014.05.019 Epub 2014 May 29. Review.

41. De Die-Smulders CE, Höweler CJ, Thijs C, Mirandolle JF, Anten HB, Smeets HJ, Chandler KE, Geraedts JP. (1998) age and causes of death in adult-onset myotonic dystrophy. Brain. 1998;121(Pt 8):1557-63.

42. Echenne B, Rideau A, Roubertie A, Sébire G, Rivier F, Lemieux B. Myotonic dystrophy type I in childhood long-term evolution in patients surviving the neonatal period. Eur J Paediatr Neurol. 2008;12(3):210-23.

43. Mathieu J, Allard P, Potvin L, Prévost C, Bégin P. A 10-year study of mortality in a cohort of patients with myotonicdystrophy. Neurology. 1999;52(8): 1658-62.

44. French National plan on rare diseases. Orphanet. 2006. http://www.orpha. net/actor/EuropaNews/2006/doc/French_National_Plan.pdf

45. López de Munain A, Blanco A, Emparanza JI, Poza JJ, Martí Massó JF, Cobo A, Martorell L, Baiget M, MartínezLage JM. Prevalence of myotonic dystrophy in Guipúzcoa (Basque Country, Spain). Neurology. 1993;43(8): $1573-6$

46. Landais P, Messiaen C, Rath A, Le Mignot L, Dufour E, Ben Said M, Jais JP, Toubiana L, Baujat G, Bourdon-Lanoy E, Gérard-Blanluet M, Bodemer C, Salomon R, Aymé S, Le Merrer M. Verloes a; CEMARA task force. CEMARA an information system for rare diseases. Stud Health Technol Inform. 2010; 160(Pt 1):481-5.

47. Giraud T, Lambert N. Cartography: create and integrate maps in your R workflow. JOSS. 2016;1 (4). https://doi.org/10.21105/joss.00054.

48. Bivand RS, Pebesma E, Gomez-Rubio V. Applied spatial data analysis with R; 2013.
49. Distribution of French population. INSEE: https://www.insee.fr/fr/statistiques/ 2119468? sommaire $=2119504$ ttop.

50. Therneau, T., Grambsch, P., Modeling Survival Data: Extending the Cox Model. Springer-Verlag, 2000.

51. Therneau TM, Grambsch PM, Pankratz VS. Penalized survival models and frailty. J Comput Graph Stat. 2003;12:156-75.

52. Dogan C, De Antonio M, Hamroun D, Varet H, Fabbro M, Rougier F, Amarof K, Arne Bes MC, Bedat-Millet AL, Behin A, Bellance R, Bouhour F, Boutte C, Boyer F, Campana-Salort E, Chapon F, Cintas P, Desnuelle C, Deschamps R, Drouin-Garraud V, Ferrer X, Gervais-Bernard H, Ghorab K, Laforet P, Magot A, Magy L, Menard D, Minot MC, Nadaj-Pakleza A, Pellieux S, Pereon Y, Preudhomme M, Pouget J, Sacconi S, Sole G, Stojkovich T, Tiffreau V, Urtizberea A, Vial C, Zagnoli F, Caranhac G, Bourlier C, Riviere G, Geille A, Gherardi RK, Eymard B, Puymirat J, Katsahian S, Bassez G. Gender as a modifying factor influencing myotonic dystrophy type 1 phenotype severity and mortality: a nationwide multiple databases cross-sectional observational study. PLoS One. 2016; 11(2).

53. Wood L, Bassez G, Bleyenheuft C, Campbell C, Cossette L, Jimenez-Moreno AC, Dai Y, Dawkins H, JAD M, Dogan C, El Sherif R, Fossati B, Graham C, Hilbert J, Kastreva K, Kimura E, Korngut L, Kostera-Pruszczyk A, Lindberg C, Lindvall B, Luebbe E, Lusakowska A, Mazanec R, Meola G, Orlando L, Takahashi MP, Peric S, Puymirat J, Rakocevic-Stojanovic V, Rodrigues M, Roxburgh R, Schoser B, Segovia S, Shatillo A, Thiele S, Tournev I, van Engelen B, Vohanka S, Lochmüller $\mathrm{H}$. Eight years after an international workshop on myotonic dystrophy patient registries: case study of a global collaboration for a rare disease. Orphanet J Rare Dis. 2018;13(1):155.

54. Wood L, Bassez G, van Engelen B, Lochmüller H, Schoser B. 222nd ENMC workshop participants. 222nd ENMC international workshop: myotonic dystrophy, developing a European consortium for care and therapy, Naarden, the Netherlands, 1-2 July 2016. Neuromuscul Disord. 2018;28(5): 463-9.

55. Ashizawa T, Gagnon C, Groh WJ, Gutmann L, Johnson NE, Meola G, Moxley R 3rd, Pandya S, Rogers MT, Simpson E, Angeard N, Bassez G, Berggren KN, Bhakta D, Bozzali M, Broderick A, Byrne JLB, Campbell C, Cup E, Day JW, De Mattia E, Duboc D, Duong T, Eichinger K, Ekstrom AB, van Engelen B, Esparis B, Eymard B, Ferschl M, Gadalla SM, Gallais B, Goodglick T, Heatwole C, Hilbert J, Holland V, Kierkegaard M, Koopman WJ, Lane K, Maas D, Mankodi A, Mathews KD, Monckton DG, Moser D, Nazarian S, Nguyen L, Nopoulos P, Petty R, Phetteplace J, Puymirat J, Raman S, Richer L, Roma E, Sampson J, Sansone V, Schoser B, Sterling L, Statland J, Subramony SH, Tian C, Trujillo C, Tomaselli G, Turner C, Venance S, Verma A, White M, Winblad S. Consensusbased care recommendations for adults with myotonic dystrophy type 1. Neurol Clin Pract. 2018.

56. Hogrel JY, Ollivier G, Ledoux I, Hébert L, Eymard B, Puymirat J, Bassez G. Relationships between grip strength, myotonia, and CTG expansion in myotonic dystrophy type 1. Ann Clin Transl Neurol. 2017;4(12):921-5.

57. Brignol TN, Leveziel N, Dogan C, Moussu-Haudebourg H, Bassez G. Retinal involvement in type 1 myotonic dystrophy: literature review and presentation of a project based on the DM-scope. J Fr Ophtalmol. 2018; 41(9):e445-6.

58. Michon CC, Miljkovitch R, Cyrulnik B. Non-verbal communication in patients with DM1 and FSHD. Med Sci (Paris). 2018;34(Hors série n²):9-12.

59. Lagrue E, Dogan C, De Antonio M, Audic F, Bach N, Barnérias C, Bellance R, Cances C, Chabrol B, Cuisset JM, Desguerre I, Durigneux J, Espil C, Fradin M, Héron D, Isapof A, Jacquin-Piques A, Journel H, Laroche C, Laugel V, Magot A, Manel V, Mayer M, Péréon Y, Perrier J, Peudenier S, Quijano-Roy S, RagotMandry S, Richelme C, Rivier F, Sabouraud P, Sarret C, Testard H, Vanhulle C, Walther-Louvier U, Gherardi R, Hamroun D, and Bassez G. A large multicenter study of pediatric myotonic dystrophy type 1 for evidencebased management. [IN PRESS].

60. Tomé $S$, Dandelot $E$, Dogan $C$, Bertrand A, Geneviève D, Péréon Y, DM contraction study group, Simon M, Bonnefont JP, Bassez G, Gourdon G. Unusual association of a unique CAG interruption in 5' of DM1 CTG repeats with intergenerational contractions and low somatic mosaicism. Hum Mutat. 2018;39(7):970-82.

61. Bassez G, Audureau E, Hogrel JY, Arrouasse R, Baghdoyan S, Bhugaloo $H_{\text {, }}$ Gourlay-Chu ML, Le Corvoisier P, Peschanski M. Improved mobility with metformin in patients with myotonic dystrophy type $1:$ a randomized controlled trial. Brain. 2018;141(10):2855-65.

62. Van Engelen B, OPTIMISTIC Consortium. Cognitive behaviour therapy plus aerobic exercise training to increase activity in patients with myotonic 
dystrophy type 1 (DM1) compared to usual care (OPTIMISTIC): study protocol for randomised controlled trial. Trials. 2015;16:224.

63. Okkersen K, Jimenez-Moreno C, Wenninger S, Daidj F, Glennon J, Cumming S, Littleford R, Monckton DG, Lochmüller H, Catt M, Faber CG, Hapca A, Donnan PT, Gorman G, Bassez G, Schoser B, Knoop H, Treweek S, Van Engelen BGM, OPTIMISTIC consortium. Cognitive behavioural therapy with optional graded exercise therapy in patients with severe fatigue with myotonic dystrophy type 1: a multicentre, single-blind, randomised trial. Lancet Neurol. 2018;17(8):671-80.

64. Thompson R, Schoser B, Monckton DG, Blonsky K, Lochmüller H. Patient registries and trial readiness in myotonic dystrophy--TREAT-NMD/Marigold International workshop report. Neuromuscul Disord. 2009;19(12):860-6.

65. Wahbi K, Porcher R, Laforêt P, Fayssoil A, Bécane HM, Lazarus A, Sochala M, Stojkovic T, Béhin A, Leonard-Louis S, Arnaud P, Furling D, Probst V, Babuty D, Pellieux S, Clementy N, Bassez G, Péréon Y, Eymard B, Duboc D.

Development and validation of a new scoring system to predict survival in patients with myotonic dystrophy type 1. JAMA Neurol. 2018.

66. Scailteux LM, Droitcourt C, Balusson F, Nowak E, Kerbrat S, Dupuy A, Drezen E, Happe A, Oger E. French administrative health care database (SNDS): the value of its enrichment. Therapie. 2018.

67. Bosco G, Diamanti S, Meola G, DM-CNS Group. Workshop report: consensus on biomarkers of cerebral involvement in myotonic dystrophy, 2-3 December 2014. Milan, Italy Neuromuscul Disord. 2015;25(10):813-23.

68. Gagnon C, Heatwole C, Hébert LJ, Hogrel JY, Laberge L, Leone M, Meola G, Richer L, Sansone V, Kierkegaard M. Report of the third outcome measures in myotonic dystrophy type 1 (OMMYD-3) international workshop Paris, France, June 8, 2015. J Neuromuscul Dis. 2018;5(4):523-37.

Ready to submit your research? Choose BMC and benefit from:

- fast, convenient online submission

- thorough peer review by experienced researchers in your field

- rapid publication on acceptance

- support for research data, including large and complex data types

- gold Open Access which fosters wider collaboration and increased citations

- maximum visibility for your research: over $100 \mathrm{M}$ website views per year

At $\mathrm{BMC}$, research is always in progress.

Learn more biomedcentral.com/submissions 